\title{
Says Who?: How News Presentation Format Influences Perceived Believability and the Engagement Level of Social Media Users
}

\author{
Antino Kim \\ Kelley School of Business \\ Indiana University \\ antino@indiana.edu
}

\author{
Alan R. Dennis \\ Kelley School of Business \\ Indiana University \\ ardennis@indiana.edu
}

\begin{abstract}
We investigate whether the news presentation format affects the believability of a news story and the engagement level of social media users. Specifically, we test to see if highlighting the source delivering the story can nudge the users to think more critically about the truthfulness of the story that they see, and for obscure sources, whether source ratings can affect how the users evaluate the truthfulness. We also test whether the believability can influence the users' engagement level for the presented news post (e.g., read, like, comment, and share). We find that such changes in the news presentation format indeed have significant impacts on how social media users perceive and act on news items.
\end{abstract}

Keywords: Fake news, social media, story format, source highlighting, source rating.

\section{Introduction}

"On the Internet, nobody knows you're a dog" [34]. The famous New Yorker cartoon suggests that on the Internet, you are anonymous, and the unspoken corollary is that deception in the cyberworld is easy because you can pretend to be whatever you wanta dog or not. Deception has been a long-running problem, and it rose to global attention in 2016 with the US presidential election, where deception in the form of "fake news" was deliberately created as part of a disinformation campaign to influence the election results $[1,3]$. The prevalence of fake news has not only shaken the public's trust in journalism as a whole but also stirred up criticism towards social media service providers, such as Facebook, for not taking more proactive countermeasures [3].

News has always been questionable in its reliability; even before the rise of the Internet, some newspapers were known for their biases and potentially distorted news [9]. Today, almost $62 \%$ of adults get news from social media (primarily Facebook), and the proportion is increasing [10]. The difference with URI: http://hdl.handle.net/10125/50385

ISBN: 978-0-9981331-1-9

(CC BY-NC-ND 4.0)
Facebook is that anyone can create "news" - real or fake - and share it, and the news spreads throughout the Internet as social media users read and share it with their contacts. The quality control function has been moved from trained journalists with a putative interest in truth, to regular Internet users who have no training and often give little thought to verifying sources before spreading news. About $23 \%$ of social media users report that they have spread fake news - $16 \%$ by accident and $14 \%$ intentionally [3]. ${ }^{1}$

The purpose of this paper is to investigate whether changes to the way in which the source of "news" is presented in social media - or the Web as a wholecan "nudge" [39] social media users to make more mindful decisions about whether to believe stories and associated activities (e.g., read, like, comment, and share) which contribute to the spread of news stories. We investigate two approaches, one subtle and simple (changing the interface to highlight the source telling the story) and another that is more expensive (a source rating - not to be confused with story rating). Our results show that both have significant effects, with the subtle approach having more than one third the impact of the more expensive approach. We begin by summarizing past research leading to hypotheses, followed by the methods, results, and a discussion of the findings and their implications.

\section{Prior Theory and Research 2.1. Fake News on the Internet}

Fake news has been defined as "news articles that are intentionally and verifiably false, and could mislead readers" [1, p. 213]. Fake news has long been a problem, but many observers have noted that it

${ }^{1}$ The percentages add to more than $23 \%$ because some people have done both.

\section{H II C S S}


became increasingly important during the 2016 election in the United States [4], where it may have actually influenced the outcome $[1,3]$. Fake news can be created for profit (e.g., click-bait advertising) or to spread propaganda and disinformation [35, 37].

In response to fake news, a number of fact checking initiatives have been launched [11]. There are many similarities and some important differences among the different initiatives [11, 22], and fact checking has been shown to influence the perceived credibility of a person or a story [41]. However, one problem with fact checking is that it occurs after the story is made public [32]. News articles tend to have a short "shelf life," and by the time fact checking has taken place, the articles would most likely have gone through their life cycle; fact checking individual stories is simply too slow. Several technical solutions attempt to automate fact checking, such as Truthy [31] and Hoaxy [32], so that results can be provided more quickly. Among them, Hoaxy is probably the best known technical solution. It searches fact checking sites that verify news stories (e.g., snopes.com, politifact.com, and factcheck.org) and sites that have a history of publishing fake news to build a database of stories. It routinely monitors the spread of stories in real time (e.g., by monitoring Twitter and RSS feeds) and displays both the spread of stories, and their fact checking.

In this paper, we present two alternatives to fact checking, both of which provide information that may influence the believability of stories in real time, at the same time as the potentially fake (or true) stories are posted on social media. In the sections below, we begin with information processing in social media and the effects of confirmation bias. We then turn to the two approaches that we propose: A change in the presentation format, and source reliability ratings.

\subsection{Information Processing in Social Media}

Most individuals use social media for hedonistic purposes [13] such as seeking entertainment or connecting with friends [17], rather than utilitarian ones such as completing work tasks. Research suggests that individuals in a hedonistic mindset may be less likely to critically consider information than those with a utilitarian mindset, as their consumption is tied to what they desire the reality to be, rather than what they know to be real [14].

Facebook tracks and learns users' preferences in stories by tracking what they read and the actions that they take (e.g., like, comment, and share). As a commercial entity, Facebook aims to maximize user satisfaction, and thus, it deliberately displays more stories matching the users' choices, so that the users see more stories that match their existing beliefs [42]. Such a process causes a decrease in the range of information that the users encounter, and, as a result, Facebook users often exist in small information bubbles - often referred to as echo chambers [4] - that reinforce their beliefs and make them believe that the world is more like them [42].

When individuals encounter information that challenges their pre-existing beliefs, they experience cognitive dissonance [8]. Suppose that an individual is presented with two contradictory facts both of which are plausible (e.g., John is honest, but a story says he lied). Since both cannot be true at the same time, this individual must resolve the inconsistency, either by concluding that the two facts are not contradictory (e.g., John lied, but he is still honest because lying is not related to honesty), or by accepting one and rejecting the other (e.g., John is honest and thus I do not believe he lied; or John lied and thus I do not believe he is honest) [8].

Resolving such a cognitive dissonance takes cognitive effort, and humans tend to be cognitive misers who resist expending effort [33]. This tendency is exacerbated when humans are in a hedonistic mindset [14]. Because rejecting the new information is cognitively simpler than reassessing one's pre-existing beliefs, most people retain their existing belief and discard the new information as being false $[5,20,25]$. This tendency to favor information that confirms one's preexisting beliefs and ignore information that challenges them is called confirmation bias $[5,20,30]$. Thus, people are more likely to believe information that matches their pre-existing views (i.e., attitude homophily or alignment $[1,15]$ ):

H1: Pre-existing beliefs directly influence the extent to which a story is perceived to be believable.

\subsection{News Story versus Story}

In the physical world, people care a great deal about the source of a news story that they hear [24]. When someone tells us something new, we are naturally attuned to the veracity of the speaker. We accept new information from those we trust and believe to be experts on the topic [16, 24], and discount news from those we distrust or from those whom we know have a history of being gullible and falling for false stories. For example, suppose one of your colleagues told you that the accounting server had been hacked and your firm had lost $\$ 2$ million. Would you

Page 3956 
believe it? Part of your perception would be driven by pre-existing beliefs about computer security at your firm (i.e., confirmation bias), and part would be influenced by the person who told you the story (e.g., whether he or she has expert knowledge and is deemed trustworthy).

So why is the online world different? Why do we pay less attention to the source of a news story on social media than to the headline? In the online world, stories are often presented as "news" (closely akin to "fact") without much emphasis on who is telling the story. We focus on Facebook because it is currently the most ubiquitous social media platform in the world, with more than 1.8 billion users [3]. Figure 1 shows a news story posted on Facebook. The design highlights the story headline and presents the item as we might see an article on a news site such as $A B C$ News or The Wall Street Journal.

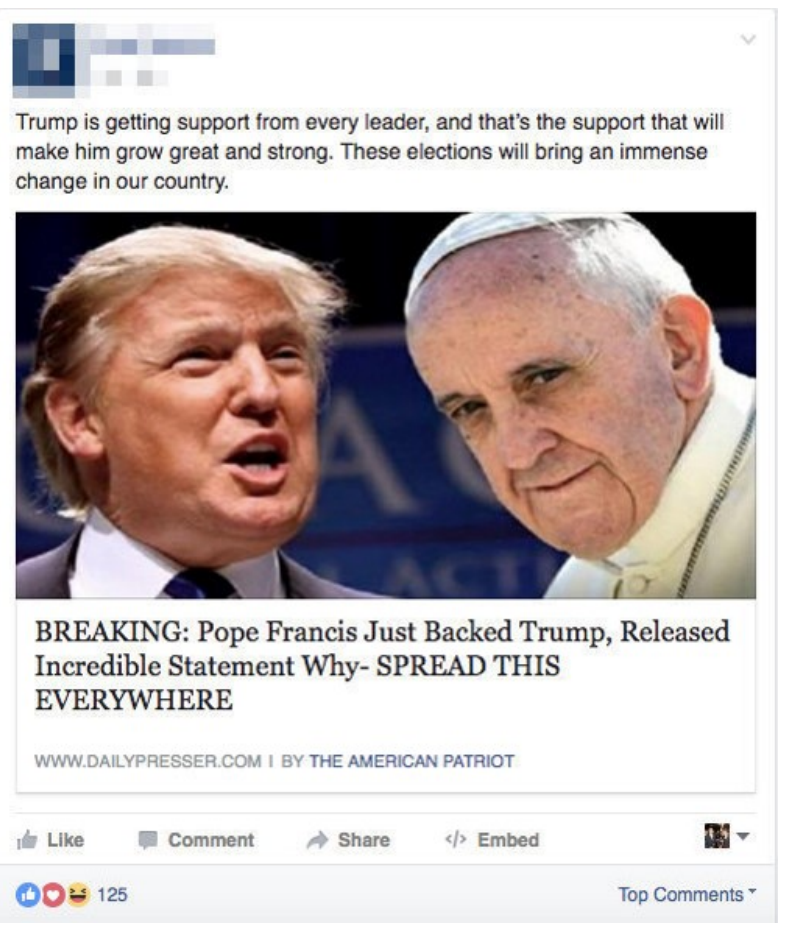

Figure 1. An example of Facebook news post

This subtle framing of a Facebook story as "news" not as a "story" influences how we process it; we adopt the mindset for processing "news," not the mindset for processing "stories." News is expected to be properly sourced and vetted to prevent intentional bias or unintentional error [40, 44]. Stories are content written by an original source that may have been subjected to the journalistic standards of news - or may not! If the original source is a recognized news source (e.g., ABC News), then it is more likely that the story has been subjected to journalistic standards than if it is written by an individual acting on his or her own.

If we can nudge [39] social media users to perceive content as stories, not news (i.e., so they are not perceived as factual news but rather as stories told by a specific person or organization), we may induce a more skeptical mindset, the same skeptical mindset that we instinctively use when we hear stories in the physical world.

We propose that framing social media content as stories, as opposed to news, can be achieved by two subtle changes in interface design that together will nudge [39] users to adopt a different mental model when reading a news story on social media.

\subsubsection{Source-primacy vs. content-primacy.}

The first change is to highlight the source of the story (i.e., the original author) rather than the headline. In the physical world, who says something always comes before the content. When we talk with people, we see who they are before we process what they say. Likewise on a phone call, we process who is talking before we consider the content.

In this source-primacy world, we use our a priori knowledge of the source when we are presented with a story, and our knowledge of the source shapes how we evaluate the content [16]. We are more likely to believe information from sources we trust and are less likely to accept information from sources we distrust or simply do not know [24]. Thus, our a priori knowledge of the source directly influences how we process information.

Currently on Facebook, the original source of a story is placed after the content in an inconspicuous manner (see Figure 1). While a user could read the article from the bottom up, in most countries, people read from top to bottom. In this content-primacy world of Facebook, we read the content first and only consider the source as an afterthought, if at all. This interface design influences us to process content with no immediate consideration for the source. We argue that this presentation format disrupts the normal consideration of source that occurs in a sourceprimacy presentation and makes users more likely to accept the content without the normal and automatic consideration of the source that occurs in a source-primacy world. ${ }^{2}$

\footnotetext{
${ }^{2}$ Google also uses this content-primacy approach in presenting search results.
}

Page 3957 
Adapting the current content-primacy Facebook interface design to be source-primacy is simple: place the source before the content and highlight the source in a way that will induce users to read it before they read the content.

2.3.2. Story teller versus reporter. To help frame the content as a story, not a news item, we need to show the reader that the source is telling the reader, not reporting facts in the manner of a journalist. Figure 2(a) shows this framing. After the source, the word "says" has been added to induce users to consider the following post as what a story teller says, not what a reporter reports. In other words, the content is what the source has to say, not a formal news story produced by a journalist, unless, of course, the source is a formal news organization known for its journalistic integrity.

2.3.3. Summary We argue these two interface design changes (source-primary with a story teller) will nudge users into a more skeptical mindset since the story framing will nudge users to read the content as a "story" not as "news". As a result, they will adopt more skeptical information processing and will be less likely to believe the story without expending cognitive effort. In short, there will be a main effect:

H2: Content presented in the story format will be perceived as less believable than content presented in the news format.

As users exert more cognitive effort to assess the truthfulness of the story, the effects of the source will become more important. Just as in the physical world, stories from trusted sources will be more likely to be evaluated as true than stories from untrusted obscure sources. In other words, there will be an interaction between whether the users trust the source and the presentation format, such that the presentation format will moderate the effects of the users' trust on the believability of story.

H3: Presentation format will moderate the relationship between whether the users trust the source and a story's believability, such that the story format will increase the strength of the impact from the users' trust in the source on the story's believability.

\subsection{Source Ratings}

One crucial limitation of fact checking each story is that fact checking occurs long after the original story has been posted. By the time the story has been fact-checked, many users would have already read the story and much of the damage from fake news would have already been done. An important alternative to fact checking all the stories is to rate the original sources (e.g., authors or sites) on the past stories the sources have produced and use those historical ratings as a predictor of the credibility of future stories. Such a source reliability measure can easily leverage the idea of fact checkers.

Source reliability is the extent to which the source is seen as producing valid statements, and it affects the extent to which we believe a specific story to be credible, although there are story-specific factors as well $[27,43]$. Source reliability in social media is influenced by past performance and is gradually built by a history of behavior that displays experience, expert knowledge, and reliable information [38].

Source reliability often requires direct personal experience with the source [38], but there are other mechanisms that can be a substitute. For example, platforms could collect ratings on each and every item (i.e., story) from users and then create an overall rating for the source. Alternatively, users could directly vote up or down the sources, and the votes can be aggregated to represent the source rating. Or, an expert panel could assess specific stories (e.g., www.politifact.com) and subsequently rate the sources. For our research, we treat the source rating system as a black box as the mechanism behind the ratings is less important than how the ratings are perceived by users. Here, we assume that the ratings are created by aggregating the ratings of an expert panel assessing prior stories produced by the source. Past research shows that fact checking individual stories or points influences perceived believability [41], so we argue that the aggregation of these individual items will also have a similar effect:

H4: Source reliability ratings will directly affect the believability of stories.

\subsection{Effects on Behavior}

Thus far, we have focused on the how social media users assess the believability of news posts they see. This believability, in turn, can affect the actions of the users. They can choose to read the story or not, and they can also choose to provide feedback on the story (e.g., like or comment) as well as contribute to the spread of story (e.g., share). Each of these actions is separate and distinct; you can like, comment on, or share a story without reading it, although most people exhibit some coherence in their behavior - reading before liking, sharing only if

Page 3958 
one read and liked a story (sometimes without clicking the Like button), and so on [18].

We argue that behavior is influenced by preexisting beliefs and the believability of the story. A user is more likely to read a story if the story is congruent with his or her prior beliefs due to confirmation bias [2]. Confirmation bias often causes selective information search $[2,19]$, in which people actively seek information that confirms their beliefs and avoid information that does not. Selective information search will be intensified when people are in a hedonistic mindset because they are not seeking to find a correct utilitarian outcome (e.g., determining whether a view is correct), but rather are seeking entertainment and enjoyment. Viewing information that supports your beliefs is more enjoyable than viewing information that challenges them [8, 26], so people will be more likely to read stories that support their pre-existing beliefs.

Other types of actions available on Facebooksuch as like, comment, and share - are unequally distributed [12, 21]. Most users seldom engage in these behaviors, perhaps because they require move cognitive effort than simply reading $[18,28]$. Nonetheless, those users that engage in these behaviors do so relatively often $[12,21]$. It may be that most users engage in casual reading behavior (which is passive and not observable to other users), but only those who are very active on Facebook choose to engage in more active behaviors that are observable to other users. It may also be that people with certain personality traits are more or less likely to engage in these behaviors [21]. The choice to act on a story can be influenced by emotion or information, with liking being driven more by emotion, commenting more by cognition, and sharing by both [18].

Therefore, we theorize that one important factor influencing the decision to read, like, comment on or share social media stories is the fit with pre-existing beliefs. The stronger the fit, the more likely the story is to trigger an emotional reaction leading to a Like, or to trigger a cognitive reaction leading to a comment, or to both, leading to sharing. Thus:

H5: Pre-existing beliefs influence the choice to read, like, comment on, and share a news story.

We argue that a second important factor influencing the decision to act on news stories is the extent to which a user believes the story to be true. Believability can be an important factor in the use of social media information [17] because if someone does not perceive information to be true, they are less likely to engage in it or to encourage its spread by sharing it. Thus:

H6: The believability of a story influences the choice to read, like, comment on, and share the story.

We argue that the primary factors affecting user behavior are pre-existing beliefs (confirmation bias) and the believability. It is possible that presentation format and source ratings may have additional effects over and above confirmation bias and believability, so we include them in our analyses, although we do not hypothesize any effects.

\section{Methodology \\ 3.1. Participants}

We recruited a total of 445 participants-125 through Facebook posts by the authors and the author's business school, and 320 from a Qualtrics panel. About 57\% were female, and about 5\% were below 24 years of age, $40 \%$ between 25 and $44,43 \%$ between 45 and 64, and $13 \%$ above 65 . For the education level, approximately $37 \%$ had not completed college, $35 \%$ had a college degree, and $28 \%$ a graduate degree.

\subsection{Task}

The participants answered a 15-minute survey that presented 12 news headlines, of which six were designed to appeal to left-leaning participants and six to right-leaning participants (see Table 1). The headlines were formatted as they might appear as posts on Facebook (see Figure 1). The headlines and images were designed to avoid major differences in the type and magnitude of feelings they would generate (i.e., one shocking headline and the other bland, one with celebrity image and the other with none, etc.). We used a genderneutral name for the poster - not to be confused with the original author-and the comment from the poster was more or less a summary of the headline itself. All these efforts were to minimize headline-specific effects, presentation-order effects, and poster-specific effects.

\subsection{Independent Variables}

There were three treatments, and all participants received all 12 headlines, with four headlines presented in each treatment. The headlines seen by each participant were randomly assigned to treatment and presented in random order within treatment (although to prevent confusion, the treatments were always in order from first to last).

Page 3959 


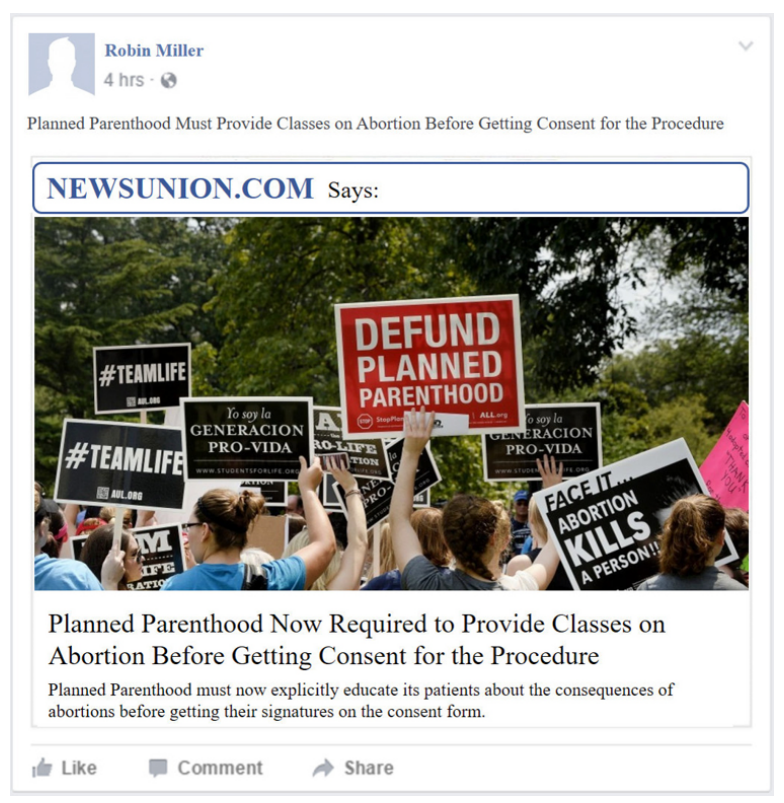

(a)

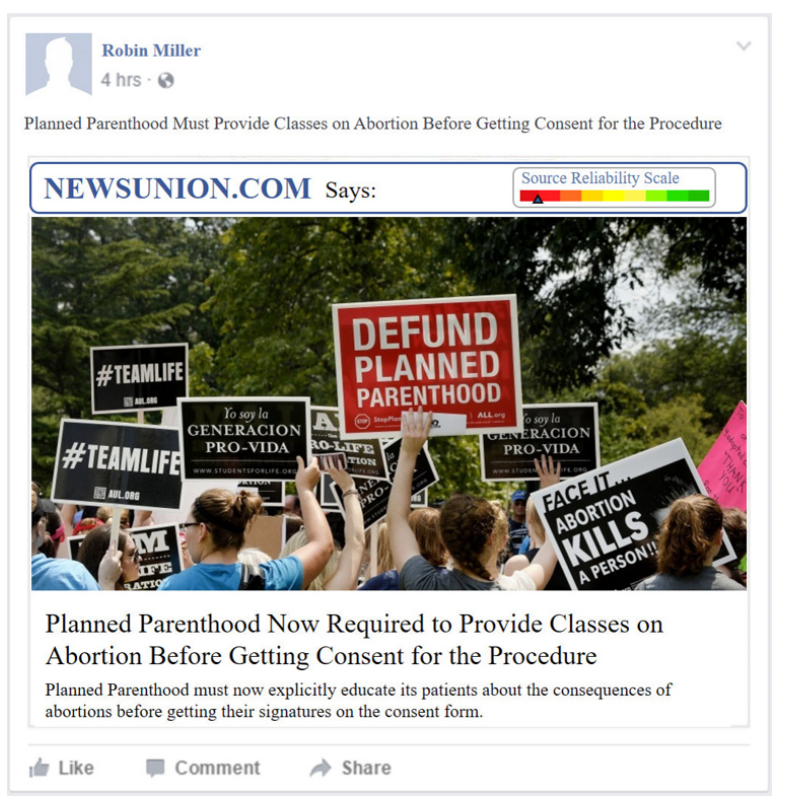

(b)

Figure 2. An example of story format with the source highlighted (a) and with source rating (b)

Table 1. The 12 news headlines used in the experiment

- The Humane Society Foundation Donates $\$ 100,000$ to Planned Parenthood After Women's March in DC

- A Republican GOP Senator Will Not Vote to Defund Planned Parenthood

- Planned Parenthood Receives a Sum of $\$ 1,000,000$ Donation from Crowd Sourcing

- Girl Scouts are Planning an Organization-Wide Fundraiser for Planned Parenthood

- Planned Parenthood Visits Campuses to Educate Young Women about the Importance of Having a Choice

- Universities Connect their Healthcare Systems with Planned Parenthood to Provide Better Care to Coeds

- Republicans Pledge to Only Fund National Pregnancy Care Center That Does Not Perform Abortions

- Pro-Life Supporters Rally in Front of Planned Parenthood Nationwide

- State Republicans Introduce New Bills to Allow Abortion Only After a Long Monitoring Period

- The State of Nevada Strengthens the Restriction on Abortion and Contraception

- Planned Parenthood Now Required to Provide Classes on Abortion Before Getting Consent for the Procedure

- On-Campus Pro-Life Supporters Significantly Reduce the Number of Abortions among Coeds

NotE: The formats of these headlines were randomized to minimize any headline-specific effects.

The first treatment was news presentation format (the control treatment) designed to mimic the cur- rent Facebook style of presentation as closely as possible. The second treatment was story presentation format with the name of the original source highlighted (see Figure 2(a)). The third treatment was story presentation format with source ratings (see Figure 2(b)). Two of the headlines were presented with high source ratings and two with low source ratings. A message was inserted before the third group of headlines to elaborate on where the ratings were hypothetically from. That way, we were able to ensure that all subjects assumed the ratings to be legitimate (i.e., offered by Facebook as opposed to by some unknown third party).

Two independent variables were self-reported by participants. The first was the affinity the participant had for the story, which was measured by multiplying the story's importance to the participant (using a 7-point scale: Do you find the issue described in the article important? $1=$ not at all, $7=$ extremely) by the participant's position on the story $(-3=$ extremely negative to +3 extremely positive). Thus, affinity ranged from -21 to +21 .

The second was whether the participant viewed the source as trusted or not. For non-trusted sources, we used ClickMedium.com, NewsUnion.com, and MediaNow.com, all of which are fabricated names but, at the same time, sound plausible enough as obscure news sources. We picked ABC News as the trusted source because ABC News has been ranked among the most trusted and well-known news outlets in the US across the political spectrum $[6,7]$. 
Nonetheless, we also asked each participant how trusted ABC News was on a 7-point scale; 120 participants did not regard $A B C$ News as a trusted source, so for them, we coded ABC News as an untrusted source.

\subsection{Dependent Variables}

The believability of each story was measured by taking the average of three 7-point items (How believable do you find this article, How truthful do you find this article, How credible do you find this article). Cronbach's alpha was adequate (0.95).

We also measured what actions the participant would take, specifically how likely the participant would be to: Read, Like, Post a supporting comment, Post an opposing comment, and Share. Each action was assessed separately.

\section{Results}

Table 2. Means and Standard Deviations for Believability

\begin{tabular}{lccc}
\hline \hline Sample Description & Mean & Std. Dev. & N \\
\hline \hline All Sources (Effect of story format) & & \\
\hline News format \& no rating & 4.806 & 1.665 & 1655 \\
\hline Story format \& no rating & 4.692 & 1.739 & 1416 \\
\hline \hline Only Obscure Sources (Effect of source rating) & \\
\hline Story format \& no rating & 4.482 & 1.728 & 905 \\
\hline Story format \& high rating & 4.980 & 1.636 & 623 \\
\hline Story format \& low rating & 4.213 & 1.918 & 615 \\
\hline \hline
\end{tabular}

The treatments means provide a first take on the results (see Table 2). The average believability for articles in the news format (i.e., no source highlighting and no rating) is higher than that for articles in the story format (without rating). For the source rating, we exclude scores from a trusted source since a trusted source would be more believable. Here, the means show that a high source rating increases believability while a low rating decreases it.

To test our hypotheses, we performed multilevel mixed-effects linear regression using STATA. About $65 \%$ of the participants omitted one or more demographics questions, so including all the demographics items in our analyses would significantly reduce our sample size. We did an initial analysis including all items and found that whether or not participants were from the Qualtrics panel had significant impacts across all dependent variables, but no other demographics item was significant in more than one of the seven analyses. Therefore, we retained the Qualtrics variable but omitted other demographics items to retain the maximum sample size. There were no differences in the statistical conclusions with or without the omitted demographics items. Table 3 presents the results: We present two models, Model 1 with just the direct effects and Model 2 with the hypothesized interaction effect.

Table 3. Estimation Results for Perceived Believability

\begin{tabular}{lcc}
\hline $\begin{array}{l}\text { Independent } \\
\text { Variables }\end{array}$ & Model 1 & Model 2 \\
\hline \hline StoryFormat & $\begin{array}{c}-0.131^{* *} \\
(0.046)\end{array}$ & $\begin{array}{c}-0.139^{*} \\
(0.059)\end{array}$ \\
\hline RatedHi & $\begin{array}{c}0.385^{* * *} \\
(0.070)\end{array}$ & $\begin{array}{c}0.389^{* * *} \\
(0.071)\end{array}$ \\
\hline RatedLow & $\begin{array}{c}-0.333^{* * *} \\
(0.076)\end{array}$ & $\begin{array}{c}-0.329^{* * *} \\
(0.076)\end{array}$ \\
\hline Trusted & $\begin{array}{c}0.405^{* * *} \\
(0.058)\end{array}$ & $\begin{array}{c}0.396^{* * *} \\
(0.076)\end{array}$ \\
\hline Trusted* & & $\begin{array}{c}0.021 \\
(0.103)\end{array}$ \\
\hline StoryFormat & $\begin{array}{c}0.477^{* * *} \\
\text { Affinity }\end{array}$ & $\begin{array}{c}0.477^{* * *} \\
(0.036)\end{array}$ \\
\hline Qualtrics & $0.537^{* * *}$ & $\begin{array}{c}0.537^{* * *} \\
(0.095)\end{array}$ \\
\hline \hline
\end{tabular}

NOTE: Estimated coefficients (and standard errors). Affinity is standardized. ${ }^{* * *} p<0.001$, ${ }^{* *} p<0.01,{ }^{*} p<0.05$.

First, this shows that Affinity has a positive and significant effect on Believability. In other words, we find the effect of confirmation bias in our study. Hence, H1 is supported.

Next, StoryFormat has a negative and significant effect on the believability of articles, supporting H2. The format that highlights the source telling the story makes the readers more critical about the believability of the presented articles.

$\mathrm{H} 3$ argued that presentation format would moderate the relationship between whether the users trust the source and the believability of stories, so that, when the source is highlighted in the story format, subjects would perceive the news articles from the trusted source more believable than those from the untrusted ones, more so than in the news format with no highlighted source. However, the interaction Page 3961 
Table 4. Estimation Results for User Actions

\begin{tabular}{lccccc}
\hline \hline $\begin{array}{l}\text { Independent } \\
\text { Variables }\end{array}$ & Read & Like & Support & Oppose & Share \\
\hline \hline \multirow{2}{*}{ Believability } & $0.531^{* * *}$ & $0.310^{* * *}$ & $0.219^{* * *}$ & $0.090^{*}$ & $0.245^{* * *}$ \\
& $(0.044)$ & $(0.034)$ & $(0.030)$ & $(0.037)$ & $(0.031)$ \\
\hline \multirow{2}{*}{ StoryFormat } & -0.110 & $-0.089^{*}$ & -0.050 & $-0.156^{* *}$ & $-0.116^{* *}$ \\
& $(0.061)$ & $(0.044)$ & $(0.042)$ & $(0.049)$ & $(0.043)$ \\
\hline \multirow{2}{*}{ RatedHi } & 0.018 & -0.090 & -0.075 & -0.045 & -0.027 \\
& $(0.065)$ & $(0.046)$ & $(0.045)$ & $(0.050)$ & $(0.047)$ \\
\hline \multirow{2}{*}{ RatedLow } & $-0.137^{*}$ & -0.018 & -0.051 & -0.027 & -0.028 \\
& $(0.062)$ & $(0.045)$ & $(0.043)$ & $(0.054)$ & $(0.045)$ \\
\hline \multirow{2}{*}{ Trusted } & 0.021 & 0.008 & 0.020 & -0.055 & 0.010 \\
& $(0.071)$ & $(0.054)$ & $(0.050)$ & $(0.048)$ & $(0.048)$ \\
\hline Trusted* & 0.089 & 0.058 & 0.018 & $0.157^{*}$ & 0.066 \\
StoryFormat & $(0.096)$ & $(0.068)$ & $(0.066)$ & $(0.067)$ & $(0.067)$ \\
\multirow{2}{*}{ Affinity } & $0.221^{* * *}$ & $0.712^{* * *}$ & $0.515^{* * *}$ & $-0.314^{* * *}$ & $0.275^{* * *}$ \\
& $(0.035)$ & $(0.044)$ & $(0.043)$ & $(0.047)$ & $(0.032)$ \\
\hline \multirow{2}{*}{ Qualtrics } & $0.672^{* * *}$ & $1.338^{* * *}$ & $1.532^{* * *}$ & $1.683^{* * *}$ & $1.581^{* * *}$ \\
\hline \hline
\end{tabular}

NOTE: : Estimated coefficients (and standard errors). Believability and Affinity are standardized. ${ }^{* * *} p<0.001,{ }^{* *} p<0.01,{ }^{*} p<0.05$.

term of Trusted ${ }^{*}$ StoryFormat is not significant, so H3 is not supported.

H4 argued that source ratings would affect believability. The coefficient for RatedHi is positive and significant whereas that for RatedLow is negative and significant, showing that rating has a significant impact on believability. Hence, H4 is supported.

Table 4 shows the analyses for users' actions. Across all actions, Affinity has a significant impact; users are more likely to read, like, and share articles that match their point of view. Commenting activities are consistent with other types of activities; users are more likely to leave supporting comments for articles that match their opinion and leave opposing comments for articles that they disagree with. In other words, confirmation bias influences users' behaviors. Hence, H5 is supported.

Table 4 also shows that Believability has a significant positive effect on all actions, indicating that users are more likely to act on articles they believe to be true. Thus, H6 is supported.

The pattern of results suggests that believability fully mediates most of the effects of story format or source rating; that is, the story format or source rating have few consistent effects on users' actions over and above their effects on believability.

\section{Discussion}

Our results show that presenting social media stories in a story format (with the source highlighted) as opposed to their current news format (where the source is suppressed) induces users to evaluate their truthfulness more critically. Likewise, presenting source ratings directly influences the believability of stories. Confirmation bias is also alive and well; our findings show that participants were more likely believe articles that they agreed with.

Perhaps one of the more interesting findings - or lack thereof - was the direct effect of presentation format on believability and the lack of an interaction between the format and whether the user trusted the source. We expected to find that users would believe articles from a trusted source more when the story format was used, but we did not find any support for the hypothesis. In other words, the story format nudges readers to subconsciously shift their thinking from reading facts to reading "stories" and this simple shift in mindset induces users to be more skeptical in evaluating the credibility of all social media articles, regardless of whether they are from a trusted source or not.

Our results also show that source ratings influence the believability of stories. When the sources are obscure, high rating boosts readers' confidence in the article that they see whereas low rating makes the readers more skeptical. The coefficients in Tables 3 and 4 are standardized, so we can assess the relative effects of presentation format versus source rating. Source ratings have about three times the effect of presentation format on believability $(.385$ and -.333 versus -.131). Interestingly, both of these have less relative impact than affinity (i.e., confirmation bias) (.477) or a trusted source (.405). 
Confirmation bias also affects users' actions. Users are more likely to read, like, post supporting comments, and share articles that they agree with (and more likely to leave opposing comments for articles they disagree with). Our results suggest that the article's believability could potentially counterbalance this effect of confirmation bias.

\subsection{Implications for Research}

We find that source ratings from a panel of experts hired by Facebook can have significant effects on the believability of the article. There are, of, course many other ways to develop source ratings. If the ratings came from common users assessing past stories (as Amazon and eBay for past purchases), would they have a stronger or weaker effect on believability than ratings from a panel of experts? If the ratings came from the users, would the mechanisms of rating matter? For instance, users can directly rate the sources, or alternatively, they could rate the articles that they read, and those ratings can be aggregated at the source level. Would there be any meaningful differences in how the users interpret these ratings from different sources and mechanisms?

Overall, our results show that presentation format and source rating affect the believability of stories, which, in turn, affects users' actions. The natural follow up question would be, "what else affects this believability?" This question is particularly important because, in Table 4, Believability has an effect on behavior comparable to Affinity. For instance, we can infer that a change of one standard deviation in Believability would have a similar impact as a change of one standard deviation in Affinity on users' sharing behavior (i.e., change of 0.245 versus 0.275 on a 7 point scale). Thus, the more we can help users leverage their critical thinking in discerning "real" news from "fake" news, the more effectively we can address the problem of fake news going viral.

Table 4 shows the relative strengths of the different factors on the actions that users can take in response to a news item-real or fake. For reading, Believability is the most important factor, being twice as important as the second most important factor, Affinity. For sharing, Believability has an effect comparable to Affinity. However, the pattern is very different for other types of behaviors such as Like, Support, and Oppose; for these, Affinity is the dominant factor, having two or three times the effect of Believability. In other words, when clicking the like button, or posting a supporting or opposing comment, users care more about whether the story supports (or opposes) their viewpoint than whether the story is true or false. This is curious because, in reality, liking a post and commenting on it also has a similar effect as sharing; users on Facebook can view posts that their friends like and comment on, and such posts appear on friends' feeds in a similar manner to shared stories. Hence, it is not clear whether the users are aware of this indirect effect of sharing through liking and commenting. Do they know they could be spreading fake news or do they care? If this effect was made clear to users, would it influence them to behave differently? Also, if it was made explicit to users regarding who will see their activities, would that also make a difference?

It is also curious that demographics such as gender, age, and education level had no significant impact on believability and actions. Is this the case in general or is it special to the online virtual world? If stories were presented in the physical world, can we expect older and more educated people to respond more critically?

Finally, another interesting aspect is the herding effect [36]. We focused on the original source of the article, not the individual who shared the article on the his or her social media feed. Would it matter who shared the article, who liked it, and how many people commented on it?

\subsection{Implications for Practice}

The public is starting to recognize the role of social media providers and search engine providers in the spread of fake news, and is calling for more proactive measures. We approach the problem of "fake news" from the opposite direction from many other researchers, who have started by first building prototypes and then testing if they affect trust; we start by first testing different news formats to see how the format affects trust and users' actions, so we can provide evidence-based design advice.

First, our results show that highlighting the source and framing the news as a "story" told by the source has an effect of making users more critical about the believability of the posts they see. Perhaps, the most important aspect of this finding is that we can nudge people to be more skeptical by making a simple and easy modification to the interface. The effects are not as strong as other options, but the proposed change is a low hanging fruit.

Second, our results show that the source rating can play an important role in how people evaluate the believability of the posts they see, which, in turn, affects their engagement with those posts (i.e., read, share, etc.). Implementation of a rating system will take time and further research may be needed to

Page 3963 
identify the best form of source ratings. We believe that the effect of such source ratings may go above and beyond what we find in this study because, in practice, many fake news are from sources that are obscure or even deceptive. The culprits interested in luring traffic to their sites for advertisement revenue may post fake news as a "click bait," and to make their scheme more effective, they may intentionally choose names that are very similar to legitimate ones such as ABCnews. com. co [23, 29]. We believe source rating can be an effective counter measure against such deceptions.

\section{References}

[1] H. Allcott and M. Gentzkow, "Social media and fake news in the 2016 election," Journal of Economic Perspectives, vol. 31, no. 2, pp. 211-236, 2016.

[2] K. Ask and P. Granhag, "Motivational sources of confirmation bias in criminal investigations: The need for cognitive closure," Journal of Investigative Psychology and Offender Profiling, vol. 2, no. 1, pp. 43-63, 2005.

[3] M. Barthel, A. Mitchell, and J. Holcomb, "Many americans believe fake news is sowing confusion," Pew Research Center, vol. 15, 2016.

[4] V. Cerf, "Information and misinformation on the internet," Communications of the ACM, vol. 60, no. 1, p. 9, 2017.

[5] P. Devine, E. Hirt, and E. Gehrke, "Diagnostic and confirmation strategies in trait hypothesis testing," Journal of Personality and Social Psychology, American Psychological Association, vol. 58, no. 6, pp. 952-63, 1990.

[6] P. Engel, "The most and least trusted news sources in America," Business Insider, December 2016. [Online]. Available: http://www.businessinsider.com/most-leasttrusted-news-outlets-sources-channel-2016-12

[7] —, "These are the most and least trusted news outlets in America," Business Insider, March 2017. [Online]. Available: http://www.businessinsider.com/most-andleast-trusted-news-outlets-in-america-2017-3

[8] L. Festinger, "A theory of cognitive dissonance," California: Stanford University Press, 1957.

[9] C. Gaziano and K. McGrath, "Measuring the concept of credibility," Journalism quarterly, vol. 63, no. 3, pp. 451-462, 1986.

[10] J. Gottfried and E. Shearer, "News use across social media platforms 2016," Pew Research, vol. 26, 2016.
[11] L. Graves, "Boundaries not drawn: Mapping the institutional roots of the global fact-checking movement," Journalism Studies, pp. 1-19, 2016.

[12] K. Hampton, L. Goulet, C. Marlow, and L. Rainie, "Why facebook users get more than they give," Pew Research Centers Internet \& American Life Project, February 2012. [Online]. Available: http://www.pewinternet.org/2012/02/03/whymost-facebook-users-get-more-than-they-give/

[13] J. C. Harsanyi, "Morality and the theory of rational behavior," Social Research, vol. 44, no. 4, p. 24, 1977.

[14] E. Hirschman and M. Holbrook, "Hedonic consumption: emerging concepts, methods and propositions," The Journal of Marketing, pp. 92-101, 1982.

[15] E. E. Housholder and H. L. LaMarre, "Facebook politics: Toward a process model for achieving political source credibility through social media," Journal of Information Technology \& Politics, vol. 11, no. 4, pp. 368-382, 2014.

[16] C. Hovland, I. Janis, and H. Kelley, "Communication and persuasion," Yale University Press New Haven CT, 1953.

[17] T. Johnson and B. Kaye, "Reasons to believe: Influence of credibility on motivations for using social networks," Computers in Human Behavior, vol. 50, pp. 544-555, 2015.

[18] C. Kim and S. Yang, "Like, comment, and share on facebook: How each behavior differs from the other," Public Relations Review, vol. 43, pp. 441449, 2017.

[19] J. Klayman, J. Busemeyer, R. Hastie, and D. Medin, "Varieties of confirmation bias," Psychology of learning and motivation: Academic Press, vol. 32, pp. 365-418, 1995.

[20] A. Koriat, S. Lichtenstein, and B. Fischhoff, "Reasons for confidence," Journal of Experimental Psychology: Human Learning and Memory, vol. 6, no. 2, pp. 107-118, 1980.

[21] S. Lee, S. Hansen, and J. Lee, "What makes us click like on facebook? examining psychological, technological, and motivational factors on virtual endorsement," Computer Communications, vol. 73, pp. 332-341, 2016.

[22] W. Lowery, "The emergence and development of news fact-checking sites," Journalism Studies, vol. 18, no. 3, pp. 367-394, 2016.

[23] J. Lu, "What is 'click bait' and why facebook wants to display less of it," The Washington Post, August 2014. [Online]. Available: https://www.washingtonpost.com/news/

Page 3964 
technology/wp/2014/08/26/what-is-click-baitand-why-facebook-wants-to-display-less-of-it

[24] McCracken, "Who is the celebrity endorse? cultural foundations of the endorsement process," Journal of consumer research, vol. 16, pp. 310-321, 1989.

[25] C. McKenzie, "Increased sensitivity to differentially diagnostic answers using familiar materials: Implications for confirmation bias," Memory $\&$ Cognition, vol. 34, no. 3, pp. 577-588, 2006.

[26] R. Minas, R. Potter, A. Dennis, V. Bartelt, and S. Bae, "Putting on the thinking cap: Using neurois to understand information processing in virtual teams," Journal of Management Information Systems, vol. 30, no. 4, pp. 49-82, 2014.

[27] J. Morris, Y. Choi, and I. Ju, "Are social marketing and advertising communications meaningful?: A survey of facebook user emotional responses, source credibility, personal relevance, and perceived intrusiveness," Journal of Current Issues 8 Research in Advertising, vol. 37, no. 2, pp. 165-182, 2016.

[28] D. Muntinga, M. Moorman, and E. Smit, "Introducing cobras: Exploring motivations for brand-related social media use," International Journal of Advertising, vol. 30, no. 1, pp. 13-46, 2011.

[29] J. Murtha, "How fake news sites frequently trick big-time journalists," Columbia Journalism Review, May 2016. [Online]. Available: https://www.cjr.org/analysis/how_fake_news_ sites_frequently_trick_big-time_journalists.php

[30] R. Nickerson, "Confirmation bias: A ubiquitous phenomenon in many guises." Review of general psychology, vol. 2, no. 2, p. 175, 1998.

[31] J. Ratkiewicz, M. Conover, M. Meiss, B. Gonçalves, S. Patil, A. Flammini, and F. Menczer, "Truthy: mapping the spread of astroturf in microblog streams," in Proceedings of the 20th international conference companion on World wide web. ACM, 2011, pp. 249-252.

[32] C. Shao, G. Ciampaglia, A. Flammini, and F. Menczer, "Hoaxy: A platform for tracking online misinformation," in Proceedings of the 25th International Conference Companion on World Wide Web. International World Wide Web Conferences Steering Committee, 2016, pp. 745-750.

[33] H. Simon, "Rational decision making in business organizations," American Economic Review, vol. 69, no. 4, pp. 493-513, September 1979.

[34] P. Steiner, "On the internet, nobody knows you're a dog," The New Yorker cartoon, 1993. [Online]. Available: https://en.wikipedia.org/wiki/ File:Internet_dog.jpg
[35] S. Subramanian, "Inside the macedonian fakenews complex," Wired, February 2017. [Online]. Available: https://www.wired.com/2017/02/velesmacedonia-fake-news/

[36] H. Sun, "A longitudinal study of herd behavior in the adoption and continued use of technology," MIS Quarterly, vol. 37, no. 4, pp. 1013-1041, December 2013.

[37] L. Sydell, "We tracked down a fake-news creator in the suburbs. here's what we learned," National Public Radio, November 2016. [Online]. Available: http://www.npr.org/sections/alltechconsidered/ 2016/11/23/503146770/npr-finds-the-head-of-acovert-fake-news-operationin-the-suburbs

[38] S. Teng, K. Khong, A. Chong, and B. Lin, "Persuasive electronic word-of-mouth messages in social media," The Journal of Computer Information Systems, vol. 55, no. 1, pp. 76-88, 2016.

[39] R. Thaler and C. Sunstein, Nudge: Improving Decisions About Health, Wealth, and Happiness. Penguin, New York, 2009.

[40] S. Wallace, "Impartiality in the news," in Journalism: New Challenges, K. Fowler-Watt and S. Allan, Eds. CJCR: Centre for Journalism \& Communication Research, Bournemouth University, 2013, pp. 65-79.

[41] A. Wintersieck, "Debating the truth: The impact of fact-checking during electoral debates," American Politics Research, vol. 45, no. 2, pp. 304-331, 2017.

[42] WSJ, "Blue feed, red feed," The Wall Street Journal, 2016. [Online]. Available: http://graphics. wsj.com/blue-feed-red-feed/

[43] T. Yang, "The decision behavior of facebook users," The Journal of Computer Information Systems, vol. 52, no. 3, pp. 50-59, 2012.

[44] B. Zhong, "Searching for meaning: Multi-level cognitive processing of news decision making among u.s. and chinese journalists," University of Maryland, pp. 15, 35, 2006. 